\title{
Poly(methyl methacrylate)-block-polystyrene and polystyrene-block-poly(n-butyl acrylate) as compatibilizers in PMMA/PnBA blends
}

\author{
Michael Stenert ${ }^{1}$, Andreas Döring ${ }^{2}$, Friedhelm Bandermann ${ }^{1}$ * \\ ${ }^{1}$ Institut für Technische Chemie, Universität Duisburg-Essen, 45117 Essen, \\ Germany; Fax 0049 2011834196; friedhelm.bandermann@uni-essen.de \\ ${ }^{2}$ Abteilung Experimentelle Physik, Universität UIm, 89069 Ulm, Germany
}

(Received: October 27, 2003; published: March 30, 2004)

Part of this work was presented at the $2^{\text {nd }}$ International Conference on Polymer Modification, Degradation and Stabilization, June 30 - July 4, 2002, Budapest, Hungary

\begin{abstract}
The influence of the addition of poly(methyl methacrylate)-blockpolystyrene (PMMA-b-PS) and PS- $b$-poly(n-butyl acrylate) (PS- $b$-PnBA) diblock copolymers on the structure and the mechanical properties of PMMA/PnBA polymer blends was investigated. In binary polymer blends of PMMA and PS, and $\mathrm{PS}$ and PnBA, and in the ternary system the corresponding diblock copolymers caused a significantly higher distribution of the dispersed phase and an appreciable narrowing of the particle size distribution as shown by scanning force microscopy using the pulsed force mode technique. Transmission electron microscopy images proved that in the ternary system the two diblock copolymers formed no own separate phase but are arranged as a ring layer at the interface between the two homopolymers PMMA and PnBA. Charpy tests demonstrated that the impact strength of the ternary blends is increased by the two diblock copolymers even at low amounts of the latter. The influence on mechanical properties like Young's modulus, yield stress, and tensile strength at break was less marked as strainstress measurements showed. The major effect seems to be exerted on the elongation at break.
\end{abstract}

\section{Introduction}

Blends offer a possibility of creating new polymeric materials with tailored technological characteristics. Based on number, type and composition of the components, the character profile can be finely matched and suited to the special application. However, the majority of polymers cannot be homogeneously mixed with each other on account of a positive mixing enthalpy (repulsive interactions) and a negligible mixing entropy, which causes phase separation of macroscopic magnitude. A high interface tension prevails at the phase interfaces and adhesion is low compared with the major polymer phases. Thus, fissures or fractures occur predominantly at the phase interfaces of the material. Large domains have a particularly negative effect. The resulting character profile tends to the negative. 
An efficient improvement can be achieved with the aid of coupling agents. Suitable coupling agents are interface-active compounds on macromolecular basis, i.e., copolymers. Computer simulations carried out by Balazs et al. [1] as well as experimental work performed by Brown et al. [2] and Teyssie et al. [3] showed that diblock and graft copolymers of the type PA- $b$ (or $g$ )-PB are of highest efficiency to couple homopolymers PA and PB. They can be added to the system as preformed polymers or formed in situ by chemical reaction during blend formation. However, the binary system of homopolymers PA and PB can also be coupled by a combination of two diblock or graft copolymers PA-b(or $g$ )-PC and PC- $b$ (or $g$ )-PB, which possess the corresponding components $\mathrm{A}$ or $\mathrm{B}$, respectively, and the common component $\mathrm{C}$, which has the effect of a buffer layer between components $A$ and $B$. This basic principle of coupling can be traced back to Balazs et al. [4,5] who had investigated blends of type PA/PA-g-PC/PC-g-PB/PB, i.e., using graft copolymers as compatibilizer. However, with the aid of living polymerization, diblock copolymers can be produced with extremely definite characteristics (e.g., narrow molar mass distribution) and thus allow an optimum interpretation of structure/property relationships. They are therefore predominantly suited for basic investigations whereas with a view to costs entailed, industrial application is restricted to a small number of systems or only possible in connection with the development of new catalysts.

The blend system of type PA/PA- $b-\mathrm{PC} / \mathrm{PC}-b-\mathrm{PB} / \mathrm{PB}$ is particularly attractive due to the fact that it can be extended to a ternary blend by adding the homopolymer component PC. Ternary blends have become increasingly important during recent years. They are considerably more complex. However, they offer a possibility, which from a technological point of view is of great importance: they can combine the three significant polymeric material groups, i.e., amorphous thermoplastics, crystalline thermoplastics and elastomers.

We have used as homopolymer PA poly(methyl methacrylate), PMMA, which is a brittle thermoplastic. To improve its fracture resistance via toughening we used poly(n-butyl acrylate), PnBA, as homopolymer PB. The interaction energy density of PMMA and PnBA $\left(0.45 \mathrm{cal} / \mathrm{cm}^{3}, 1.88 \mathrm{~J} / \mathrm{cm}^{3}\right)$ indicates that they are incompatible [6]. Xie and Zhou used graft copolymers of PnBA with PMMA macromonomers to compatibilize blends of PMMA and PnBA and to improve the degree of adhesion between the phases [7]. Several authors extended this idea to compatibilize the core and the shell polymers in a core/shell latex with PnBA as core and PMMA as outer shell [8-12]. Burford et al. studied the adhesion properties of PMMA- $b-P n B A$ diblock copolymers. They found that the peel strength in laminate joints depended on both molar mass and composition of the diblock copolymer, especially when the copolymer contained mainly a PMMA block. The adhesion was enhanced with increasing molar mass. For other PMMA/PnBA compositions no reinforcement was observed irrespective of molar mass [13].

It was the goal of our research work to investigate the effectiveness of diblock copolymers PA- $b-\mathrm{PC}$ and PC- $b-\mathrm{PB}$ as new coupling agent system both on a microscopic as well as macroscopic level. As basic component PC we selected polystyrene, PS, and as diblock copolymers PMMA- $b$-PS and PS- $b$-PnBA. The interaction energy densities of the systems PMMA/PS and PS/PnBA are positive $\left(0.22 \mathrm{cal} / \mathrm{cm}^{3}, 0.92 \mathrm{~J} / \mathrm{cm}^{3}\right.$, and $0.28 \mathrm{cal} / \mathrm{cm}^{3}, 1.17 \mathrm{~J} / \mathrm{cm}^{3}$, respectively), pointing to incompatibility of both binary systems [6]. 


\section{Experimental part}

\section{Polymer synthesis}

Molar mass distribution of all polymers should be within a narrow range and the chain or block lengths, respectively, lie above the critical entanglement molar mass, however, within a range of viscosity which allows easy handling $\left(\bar{P}_{n} \approx 500\right)$. All polymers were synthesized by way of living polymerization processes in an inert atmosphere.

The monomers methyl methacrylate (MMA), tert-butyl acrylate (tBA), styrene (S) as well as a-methylstyrene ( $\alpha \mathrm{MS}$ ) and the solvents tetrahydrofuran (THF) and toluene were stirred over $\mathrm{CaH}_{2}$ for several days and then distilled off. Organometallic compounds were used for further purification of the reaction components. MMA and tBA were diluted $(50 / 50 \mathrm{v} / \mathrm{v})$ with toluene, mixed with some millilitres of a $1.3 \mathrm{M}$ triethylaluminium solution in heptane and condensed into the reaction vessels immediately before application. Styrene was distilled in vacuum from $\mathrm{LiAlH}_{4}$. Toluene was mixed with a few drops of 1,1-diphenylethylene and some millilitres of a $10 \mathrm{M}$ secBuLi solution in heptane and then distilled. $\mathrm{LiCl}$ was dried at $130^{\circ} \mathrm{C}$ in vacuum over a period of several days. Methanol as termination agent of the anionic polymerizations was degassed and saturated with argon.

All polymers were obtained by well-known procedures published in the literature. PMMA was produced using group transfer polymerization: MMA was polymerized in THF for $1 \mathrm{~h}$ at $20^{\circ} \mathrm{C}$ with 1-methoxy-2-methyl-1-propenyloxytrimethylsilane/tetrabutylammonium bibenzoate (MTS/TBABB) as initiating system [14].

Polymerization of $S$ was initiated with sec-BuLi/aMS in toluene $\left(3 \mathrm{~h}\right.$ at $\left.60^{\circ} \mathrm{C}\right)$. PnBA was produced in a two-stage process. In the first step, tBA was polymerized with secBuLi/aMS as initiator and $\mathrm{LiCl}$ as $\mu$-ligand at $-78^{\circ} \mathrm{C}$ in THF. Subsequently, PtBA was boiled under reflux for $48 \mathrm{~h}$ in a n-butanol/p-xylene $(50 / 50 \mathrm{v} / \mathrm{v})$ mixture with $p$-toluenesulfonic acid as catalyst and in this way transformed by transesterification quantitatively to PnBA.

PMMA- $b$-PS synthesis was carried out by sequential addition of the two monomers (S being the first one); sec-BuLi/aMS served as initiator, $\mathrm{LiCl}$ as $\mu$-ligand and THF as solvent. Reaction temperature was $-78^{\circ} \mathrm{C}$, reaction period $30 \mathrm{~min}$ for each block. Traces of PS were removed by extraction with cyclohexane as selective solvent for PS. PS dissolved, PMMA- $b$-PS remained in solid state and could be separated by filtration.

PS- $b-P n B A$ was produced in a two-stage process, too: synthesis of PS- $b-P t B A$ by sequential addition of the two monomers ( $S$ being the first one); sec-BuLi/aMS served as initiator, $\mathrm{LiCl}$ as $\mu$-ligand and $\mathrm{THF}$ as solvent. Reaction temperature was $-78^{\circ} \mathrm{C}$, reaction period $30 \mathrm{~min}$ for each block. PS- $b$-PtBA was subsequently boiled under reflux for $48 \mathrm{~h}$ in a $\mathrm{n}$-butanol $/ p$-xylene $(50 / 50 \mathrm{v} / \mathrm{v})$ mixture with $p$-toluenesulfonic acid as catalyst and thus transformed by transesterification quantitatively to PS- $b$ PnBA. Traces of PS were removed by extraction with acetone as selective solvent for the diblock copolymer PS-b-PnBA. PS remained in solid state and could be separated by repeated centrifugation (30 $\mathrm{min}$ at $4000 \mathrm{rpm}$ ).

All polymer samples were characterized by means of gel permeation chromatography (GPC), differential scanning calorimetry (DSC) and quantitative ${ }^{1} \mathrm{H}$ and ${ }^{13} \mathrm{C} N M R$ spectroscopy, respectively. The GPC device consisted of a pump (model 64, Knauer, Germany), three columns MZ Sdplus (MZ Analysentechnik, Germany) and a Knauer differential refractometer. The solvent was chloroform $(1 \mathrm{~mL} / \mathrm{min})$. Standard PS, 
standard PMMA and standard PnBA were used for calibration to determine number and weight average molar mass. For diblock copolymers, PS was used as standard. NMR spectra were measured with a $500 \mathrm{MHz}$ instrument (type DRX, Bruker, Germany). $\mathrm{CDCl}_{3}$ served as solvent. Both ${ }^{1} \mathrm{H}$ as well as ${ }^{13} \mathrm{C}$ spectra were utilized for quantitative evaluation. The glass transition temperatures of polymers were measured with a Perkin Elmer DSC 7 instrument calibrated with indium $\left(T_{\mathrm{m}}=\right.$ $\left.156.6^{\circ} \mathrm{C}\right)$ and heptane $\left(T_{\mathrm{m}}=-90.6^{\circ} \mathrm{C}\right)$. Nitrogen served as purging gas. The samples were subjected to two temperature programmes, from -80 to $-20^{\circ} \mathrm{C}$ and from 50 to $150^{\circ} \mathrm{C}$, which comprise several consecutive heating-up and cooling-down cycles. In the first cycle, the thermomechanical 'history' of the sample was neutralized; the subsequent cycles could be utilized for evaluation. Heating-up rate was $20 \mathrm{~K} / \mathrm{min}$, cooling down rate $10 \mathrm{~K} / \mathrm{min}$.

\section{Production of polymer blends}

Polymer blend films were produced by way of spin coating. The polymers were dissolved in $p$-xylene as solvent. Absolute concentration was constantly $4 \mathrm{w} / \mathrm{v} \%$. The composition of blends is given in wt.-\%. Thin films were produced by applying one drop of a solution on a spinning substrate. Freshly cleaned and degreased glass slides served as support. Rotation speed was $1700 \mathrm{rpm}$ (20 s). Finally, the films were dried in vacuum at $50^{\circ} \mathrm{C}$ for $72 \mathrm{~h}$.

The film thickness, determined by comparing a surface with and without film, varied between $300 \mathrm{~nm}$ and $900 \mathrm{~nm}$, depending on type and composition of the blends. Optical microscopy (OM) investigations (type CH40, 200 - 1000-fold magnification, Olympus Optical Comp., Germany) showed that the polymer blend films formed were uniform over the entire section of $1.5 \mathrm{~cm} \times 1.5 \mathrm{~cm}$.

The polymer blend films were analyzed by scanning force microscopy (SFM, Topometrix Explorer) using the pulsed force mode technique (PFM) [15]. The measurements were performed using force modulation cantilevers (Nanosensors, type FMR, spring constant $1.2-5.5 \mathrm{~N} / \mathrm{m}$ ) under ambient conditions. Applied maximum forces were in the range of $16-73 \mathrm{nN}$ at $1 \mathrm{kHz}$ PFM frequency.

For transmission electron microscopy, TEM, pictures (type EM 900, Zeiss, Germany) thin films with $100 \mathrm{~nm}$ thickness were cut from coupling agent test samples with a microtome (type Ultracut E, Reichert Jung, Germany). These films were exposed to the vapour of a $1 \%$ aqueous $\mathrm{RuO}_{4}$ solution for $20 \mathrm{~min}$ at room temperature. Based on Sawyer and Grubb [16], PS should be coloured intensively, PnBA and PMMA not or only slightly. Since PS is only existent as one component of the diblock copolymers, these are selectively contrasted. Thus the coupling agent system could be localized.

For the production of test samples of polymer blends the polymers were dissolved in THF. Absolute concentration was constantly $5 \mathrm{w} / \mathrm{v} \%$. The composition of blends is given in wt.-\%. For precipitation of the polymers, the solution, while being intensively stirred with a perforated blade agitator, was dropped into the 5-fold quantity of a mixture of methanol/water at a ratio of $75 / 25$. The precipitated polymers were repeatedly washed, isolated and subsequently dried. The produced powder was compression moulded at $220^{\circ} \mathrm{C}$ to shape samples with a size of $80 \mathrm{~mm} \times 10 \mathrm{~mm} \times 4 \mathrm{~mm}$.

Investigations of impact strength according to Charpy were performed using a pendulum impact tester (type 568, Frank, Germany). At least four test samples were prepared in each case in order to ensure consistency of the results. 
Samples to determine stress/strain behaviour modulus were produced in a micro injection moulding machine (Ferromatic Milacion Maschinenbau GmbH, Germany). The samples were $5 \mathrm{~cm}$ long, $5 \mathrm{~mm}$ broad and $1 \mathrm{~mm}$ thick. Strain-stress measurements were performed on a universal testing machine (UTS Testsysteme $\mathrm{GmbH}$, Germany) at a rate of $0.5 \mathrm{~mm} / \mathrm{min}$ at room temperature. Tab. 1 summarizes all synthesized polymers and copolymers with some of their most important properties for our work.

Tab. 1. Applied polymers; top: in polymer blend films; bottom: in test samples pressed to shape. $\left(\bar{M}_{w}, \bar{M}_{n}=\right.$ weight-average and number-average molar mass, respectively; $D=\bar{M}_{w} / \bar{M}_{n}=$ dispersion index; $\bar{P}_{n}=$ number-average degree of polymerization; $T_{\mathrm{g}}=$ glass transition temperature; $\mathrm{md}=$ monodisperse; $\mathrm{n} . \mathrm{d}$. $=$ not determined)

\begin{tabular}{lccccccc}
\hline Polymer & $\begin{array}{c}\text { Total } \bar{M}_{w} \\
\text { in kg/mol }\end{array}$ & $\begin{array}{c}\text { Total } \bar{M}_{n} \\
\text { in kg/mol }\end{array}$ & $\begin{array}{c}\text { Compos. } \\
\text { S/A in } \\
\text { w/w }\end{array}$ & $\begin{array}{c}\bar{P}_{n} \\
\text { S-block }\end{array}$ & $\begin{array}{c}\bar{P}_{n} \\
\text { A-block }\end{array}$ & $T_{\mathrm{g}}$ in ${ }^{\circ} \mathrm{C}$ \\
\hline PMMA (md) & 55 & 50 & 1.09 & & & 501 & 118 \\
PnBA (md) & 87 & 66 & 1.32 & & & 513 & -46 \\
PS (md) & 57 & 55 & 1.02 & & 532 & & 101 \\
PMMA-b-PS 1 & 117 & 110 & 1.06 & $52 / 48$ & 508 & 573 & n.d. \\
PS-b-PnBA 1 & 127 & 113 & 1.12 & $49 / 51$ & 532 & 450 & $106 /-40$ \\
PMMA Lucryl G77 & 88 & 52 & 1.68 & & & 522 & 105 \\
PnBA Acronal var. & 124 & 46 & 2.71 & & & 356 & n.d. \\
PS 158K & 252 & 116 & 2.18 & & 1114 & & 100 \\
PMMA-b-PS 2 & 146 & 135 & 1.08 & $53 / 47$ & 607 & 712 & $123 / 103$ \\
PS-b-PnBA 2 & 152 & 137 & 1.11 & $44 / 56$ & 577 & 597 & $102 /-46$
\end{tabular}

\section{Results and discussion}

In the first part of our investigations we tried to check whether the block copolymers would arrange with their two branches at the interface of the two incompatible homopolymers in the desired way, thus causing a reduction of particle size. Therefore, we simplified the system and started with the analysis of only binary blends. The effectiveness of the individual diblock copolymers in the corresponding binary blends (PMMA- $b-P S$ in PMMA/PS blends and PS- $b-P n B A$ in PS/PnBA blends) is the basic parameter for the application of the combined coupling agent system PMMA- $b-\mathrm{PS} /$ $\mathrm{PS}-b-\mathrm{PnBA}$ in PMMA/PnBA blends.

\section{Effect of diblock copolymers on the phase behaviour of solution mixed binary blends}

Illustration of the morphology of polymer blend films produced by solution mixing (spin-coating) is usually performed by OM, scanning electron microscopy, SEM, or TEM. However, these methods entail various disadvantages. On the one hand, they produce only a two-dimensional image (top view with OM or TEM), on the other hand they require complicated sample preparation (production of thin films and contrasting 
for TEM, metal steaming for SEM) or have only a limited resolving capacity (OM). Atomic force microscopy, AFM, combines simple sample preparation, information on three-dimensional size (topography), and phase contrast by special measuring methods - pulsed force mode or tapping mode - and a high resolving capacity. Moreover, the software allows to process the digital images with a computer, i.e., to elaborate the particle size distribution.

\section{PMMA/PS blends}

Blends of PMMA and PS have been repeatedly investigated in literature, likewise the influence of various coupling agents on the morphology and the technological characteristics. Some papers deal with the effect of random copolymers of PMMA and PS as effective polymeric compatibilizers. Smith et al. [17] performed lattice Monte Carlo simulations and found that a symmetric distribution of the copolymer at the interface between the two immiscible homopolymers is obtained for asymmetric copolymers when the Flory-Huggins parameter $\chi$ is independent of the copolymer composition. For a compositional asymmetric copolymer, an asymmetric distribution of the copolymer results with composition-independent $\chi$. For an asymmetric copolymer a symmetric composition is only observed when the $\chi$ values are allowed to depend upon the copolymer composition. According to Pellegrini et al. [18] symmetric random PMMA/PS copolymers in a content of 5 to 10 vol.- $\%$ segregate only to less than $70 \%$ to the interface without forming a discrete layer. However the interface is broadened and interfacial fracture toughness and phase coalescence are reduced. Lee et al. [19] studied the effect of random PMMA/PS copolymers with 70 wt.-\% styrene and observed that during melt mixing the copolymer moves to the interface between PMMA and PS forming encapsulating layers. During annealing, the characteristic size of the dispersed phase gradually increases. Therefore, the encapsulating layer does not provide stability against static coalescence. Therefore, the authors question the effectiveness of random copolymers as practical compatibilizers.

For PMMA/PS diblock copolymers Russell et al. [20] showed in solution mixing experiments that as the content of copolymer is increased the interface between the PMMA and PS segments broadens, continuing up to a point where the interface becomes saturated with the diblock copolymer. Beyond this saturation point the copolymer begins to form ordered structures. Macosko et al. [21] deduced from melt mixing experiments that their principle role in controlling morphology appears to be in preventing coalescence. Preventing dynamic coalescence leads to size reduction, while preventing static coalescence results in stability or compatibilization. The authors guessed that less than $5 \%$ of the interface needs to be covered to prevent dynamic coalescence, while $\approx 20 \%$ is necessary to impart static stability.

We prepared PMMA/PS blend film by spin coating in the absence and the presence of PMMA-b-PS as compatibilizer. In Fig. 1, OM and AFM images are shown for blends with different contents of PMMA and PS. On the left and in the middle of row 1 in Fig. 1, the blend system PMMA/PS with a polymer ratio of 20/80 w/w is shown without addition of a coupling agent. PS is forming the background phase and PMMA as highly distributed phase the elevated one. This interpretation results from the attribution of the two polymer phases due to AFM adhesion measurements, since PS exhibits the higher adhesion power to the target surface in comparison to PMMA. On the right in row 1, the system PMMA/PMMA-b-PS/PS is shown, formed from PMMA/ PS after addition of 10 wt.-\% of PMMA-b-PS 1 as coupling agent. Its composition weight ratio was $18 / 10 / 72$ with respect to the three components PMMA, PMMA-b-PS, 
and PS, respectively, and 13.2/76.8 with respect to PMMA/PS. Again, PS forms the lower matrix, which incorporates the elevated, dispersed PMMA phase. The addition of $10 \%$ diblock copolymer leads to an appreciable decrease in PMMA particle size.

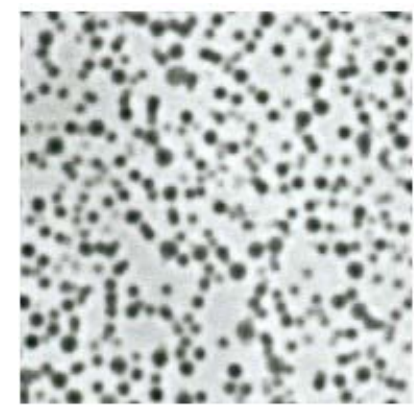

$20 / 80$

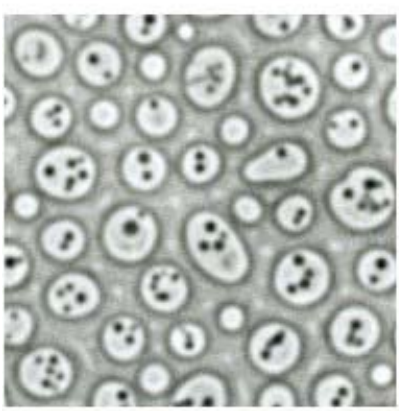

$80 / 20$

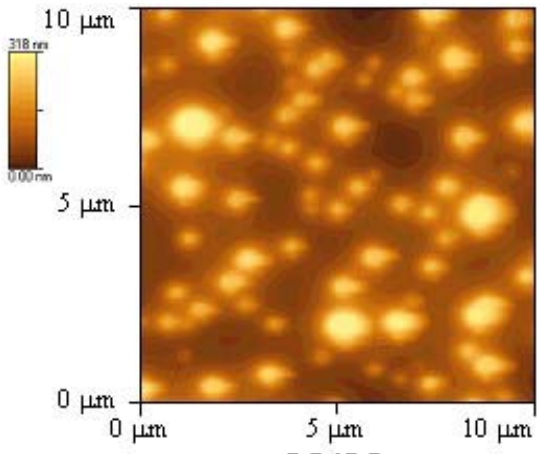

$20 / 80$

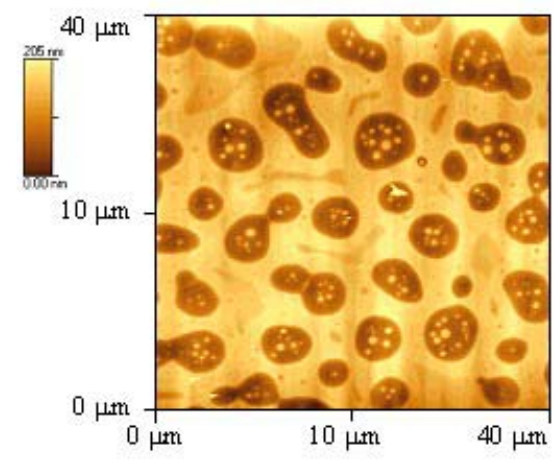

$80 / 20$

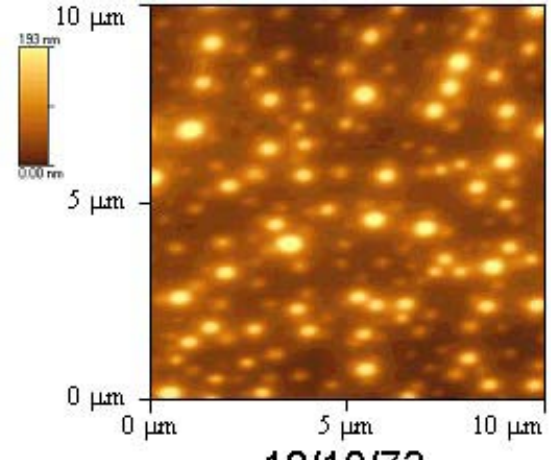

$18 / 10 / 72$

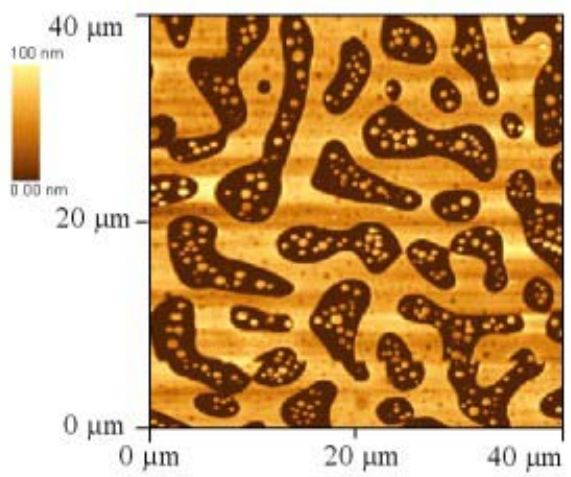

$72 / 10 / 18$

Fig. 1.OM and AFM images of polymer blends. Top left: OM image PMMA/PS (20/80); top middle: AFM image PMMA/PS (20/80); top right: AFM image PMMA/ PMMA- $b$-PS/PS (18/10/72); bottom left: OM image PMMA/PS (80/20), bottom middle: AFM image PMMA/PS (80/20), bottom right: PMMA/PMMA-b-PS/PS (72/10/ $18)$. The values in brackets correspond to the weight ratio of the components

However, as the OM picture for PMMA/PS $=80 / 20$ on the left in row 2 of Fig. 1 shows, in this case PMMA is forming the continuous phase with islands of PS, which again have incorporated some PMMA. According to the first AFM image in the middle of row 2 of Fig. 1 the interconnected PMMA structure is elevated from the PS background phase. Furthermore within the PS phase some pins of PMMA are protruding from the bottom. After the addition of $10 \mathrm{wt} .-\%$ PMMA-b-PS 1 the actual weight ratio of PMMA/PS was 77.2/22.8. Now the nearly sphere-shaped particles of PS run together to longer worm-like phases (Fig. 1, row 2, right). Of course the addition of 10 wt.-\% of the diblock copolymer increased the amount of PS in the blend. Obviously the system was already shifted to a range of composition were PS is forming more and more the continuous phase. In this case the compatibilizer acts more in distributing PMMA than PS.

The influence of the compatibilizer is unequivocal, which can also be deduced from particle size distributions of blends PMMA/PS = 20/80 and PMMA/PMMA- $b-P S / P S=$ $18 / 10 / 72$ in Fig. 2. Here, the relative frequency of particles is plotted versus the particle diameter. The relative frequency is defined as the quantity of particles in one diameter interval divided by the total number of particles. The diameter interval has 
been fixed in this case at $100 \mathrm{~nm}$. Here and in Figs. 4 and 6 the distribution data were approximated by a Gaussian curve.

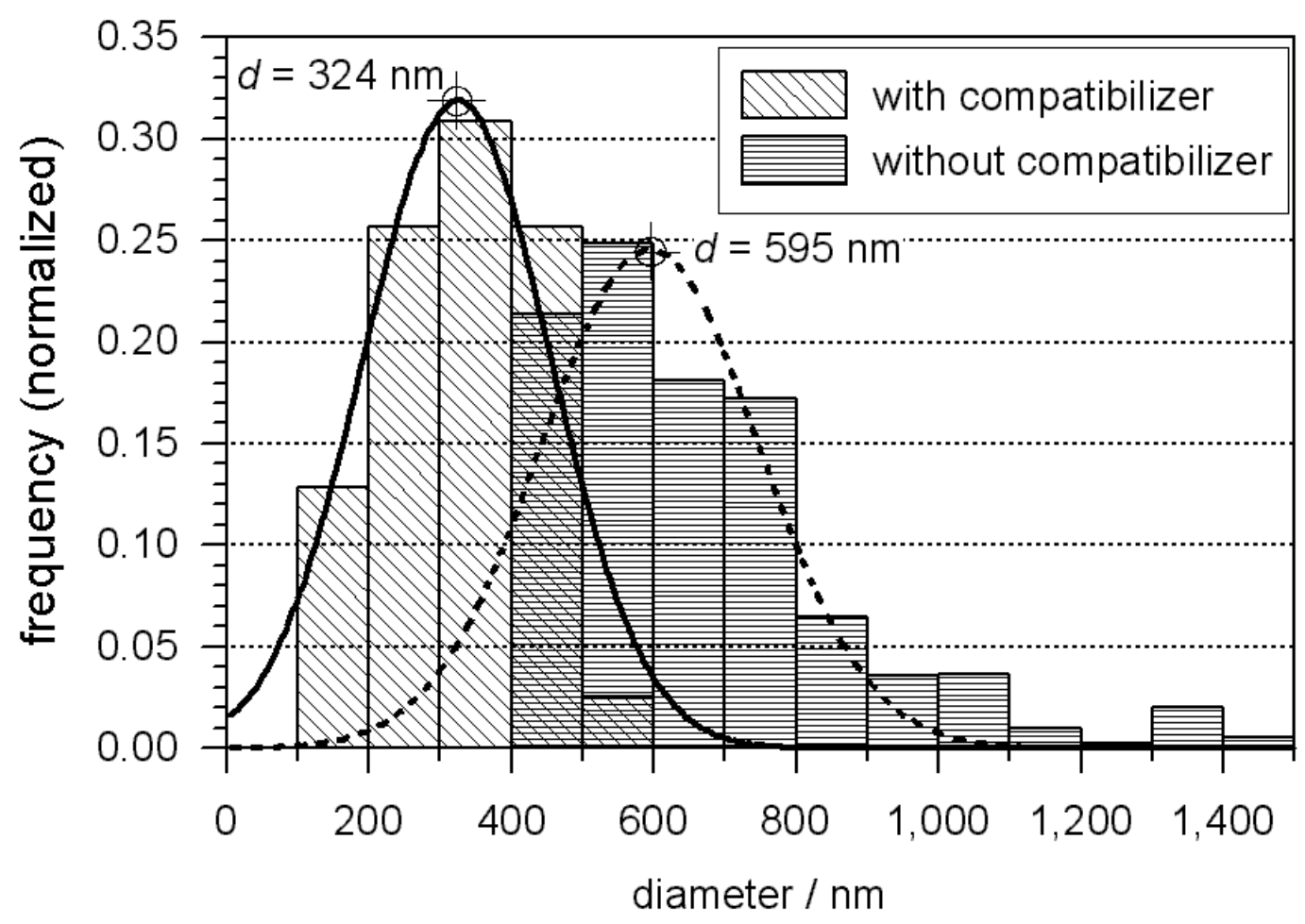

Fig. 2. Particle size distributions of the two blends $\mathrm{PMMA} / \mathrm{PS}=20 / 80$ and $\mathrm{PMMA} /$ PMMA- $b-\mathrm{PS} / \mathrm{PS}=18 / 10 / 72$ in row 1 of Fig. 1

It can be deduced that in the blend without addition of the coupling agent, the smallest PMMA particles have a diameter of about $400 \mathrm{~nm}$, the largest of about 1500 $\mathrm{nm}$. The average particle diameter is $595 \mathrm{~nm}$. In the blend PMMA/PMMA- $b-P S / P S$ (18/10/72) with addition of $10 \%$ diblock copolymer coupling agent, the smallest PMMA particles have a diameter of about $100 \mathrm{~nm}$, the largest of about $600 \mathrm{~nm}$. It is narrower than the blend without addition of a coupling agent. The average particle diameter is $324 \mathrm{~nm}$. Fig. 2 clearly demonstrates that the addition of diblock copolymers causes a significantly better distribution of the dispersed phase PMMA in the continuous PS phase and an appreciable narrowing of the particle size distribution. From the system PMMA/PS $=80 / 20$ and PMMA/PMMA- $b-P S / P S=72 / 10 / 18$ no particle size distribution could be derived.

\section{PS/PnBA blends}

Investigations of stabilization of PS/PnBA blends are scare. Vollmert substituted PnBA by free carboxyl and PS by isocyanato or $\mathrm{OH}$ groups to achieve grafting of PS on PnBA. In both cases high impact PS could be obtained [22]. Lee et al. [23] synthesized core/shell PS/PnBA latex particles by stepwise emulsion polymerization. They could show that a thin layer of a PS-g-PnBA copolymer was formed between the core $(\mathrm{PnBA})$ and shell (PS) regions that increased the compatibility between both phases.

The same influence of the addition of diblock copolymers on the dispersion and the particle size distribution as in the PMMA/PS system can be observed in the PS/PnBA 
system. Here, a system with a high PnBA and a low PS content is of interest. One $\mathrm{OM}$ and two AFM images are shown in Fig. 3.

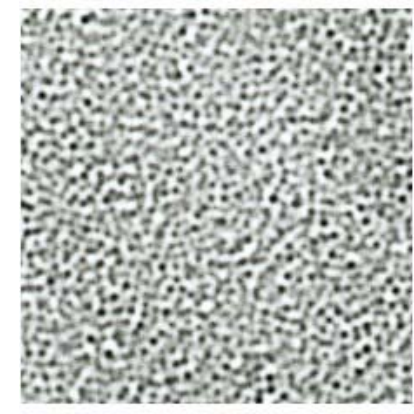

$20 / 80$
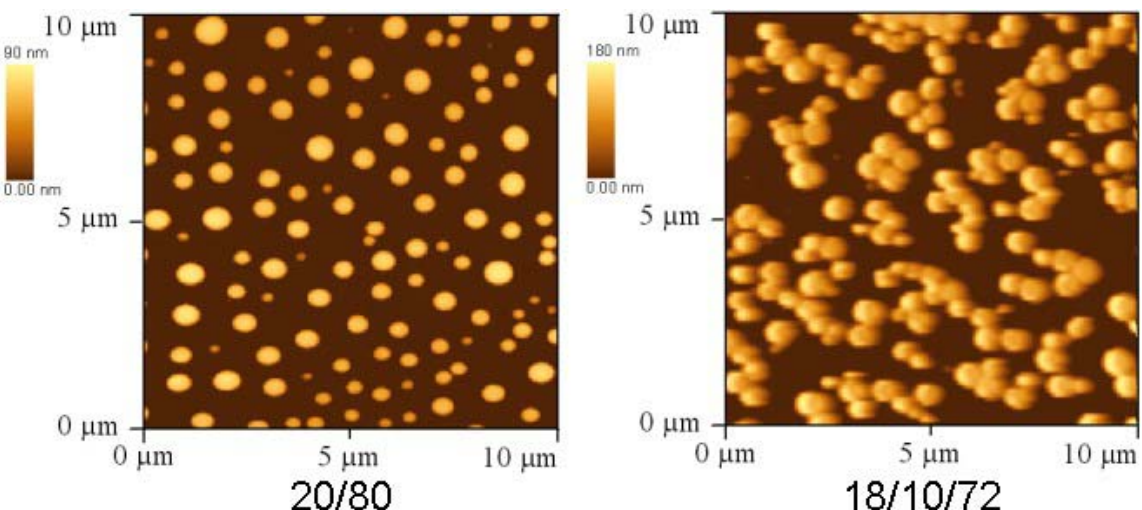

Fig. 3. OM and AFM images of polymer blends. Left and middle: PS/PnBA (20/80); right: PS/PS-b-PnBA/PnBA (18/10/72)

On the left and in the middle, the system is shown without addition of a coupling agent; the composition is PS/PnBA $=20 / 80 \mathrm{w} / \mathrm{w}$. On the right, the system is shown after addition of $10 \%$ PS- $b-P n B A 1$ as coupling agent; the composition is PS/PS- $b-$ $\mathrm{PnBA} / \mathrm{PnBA}=18 / 10 / 72 \mathrm{w} / \mathrm{w} / \mathrm{w}$ with a total ratio of $\mathrm{PS} / \mathrm{PnBA}=23 / 77$. In each case PnBA forms the dark lower matrix, which incorporates the bright, elevated, dispersed PS phase. A comparison of both AFM images shows clearly the dispersing effect of the compatibilizer, which can also be deduced from Fig. 4, which illustrates the particle size distribution.

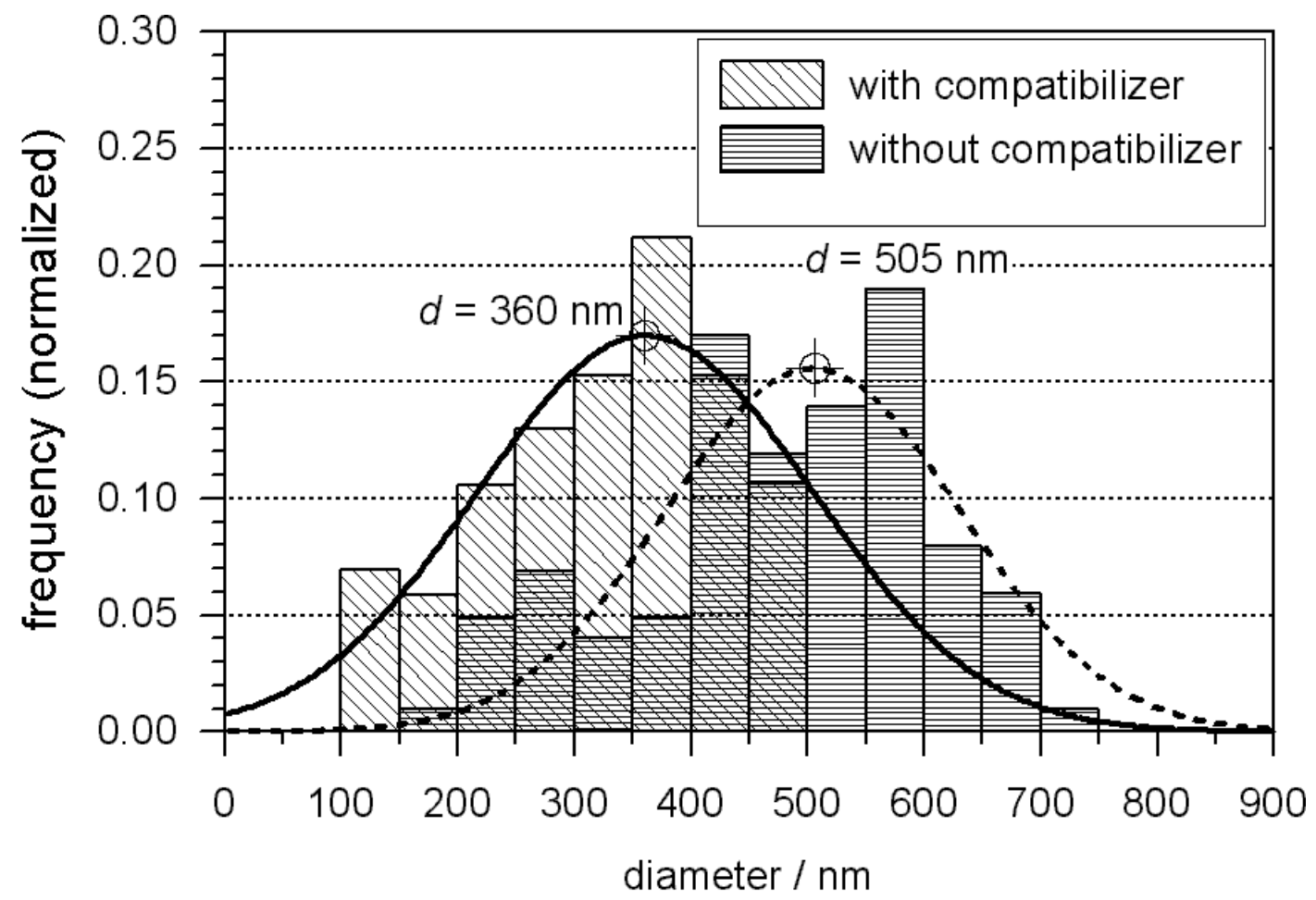

Fig. 4. Particle size distributions of the two blends PS/PnBA $=20 / 80$ and PS/PS- $b$ PnBA/PnBA $=18 / 10 / 72$ of Fig. 3 
The diameter interval has been fixed in this case at $50 \mathrm{~nm}$. In the blend PS/PnBA 20/80 without addition of the coupling agent, the smallest PS particles have a diameter of about $150 \mathrm{~nm}$, the largest of about $800 \mathrm{~nm}$; the average particle diameter is $505 \mathrm{~nm}$. In the blend with addition of $10 \%$ diblock copolymer as coupling agent the smallest PS particles have a diameter of about $100 \mathrm{~nm}$, the largest of about $500 \mathrm{~nm}$. The particle size distribution is narrower than in the blend without addition of coupling agent. The average particle diameter is $360 \mathrm{~nm}$.

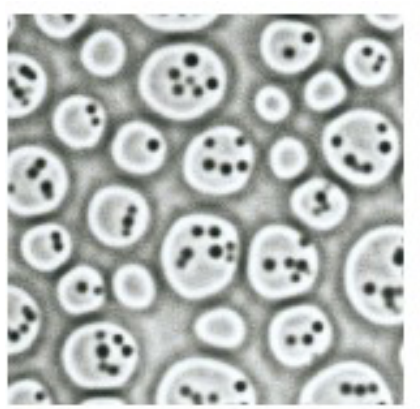

$80 / 20$

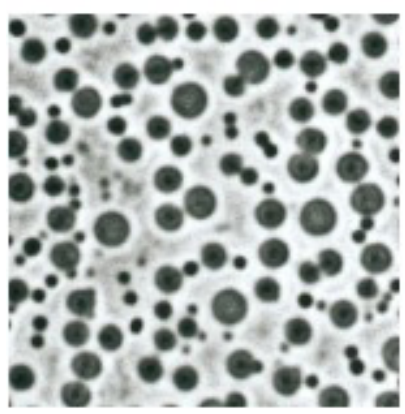

$50 / 50$

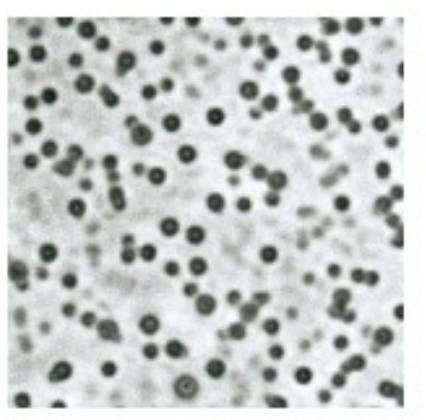

$20 / 80$

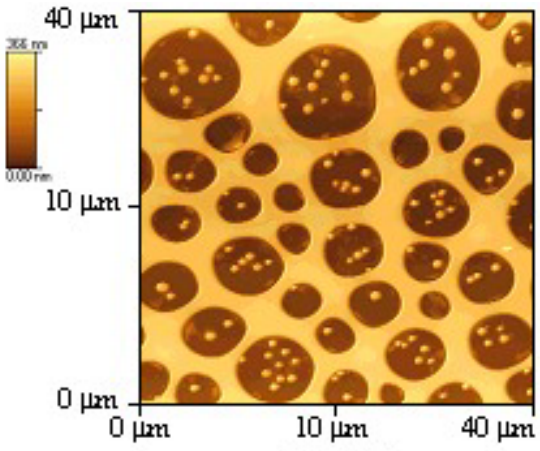

$80 / 20$

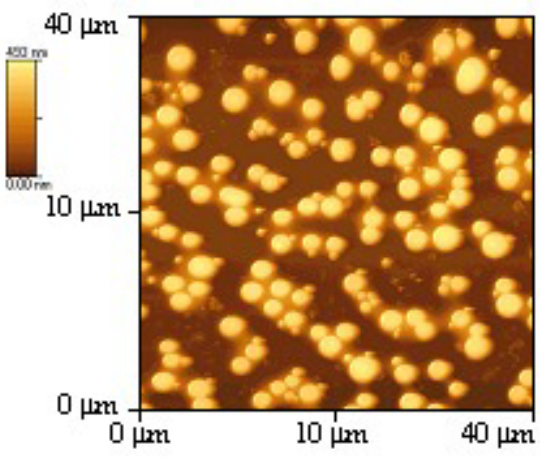

$50 / 50$

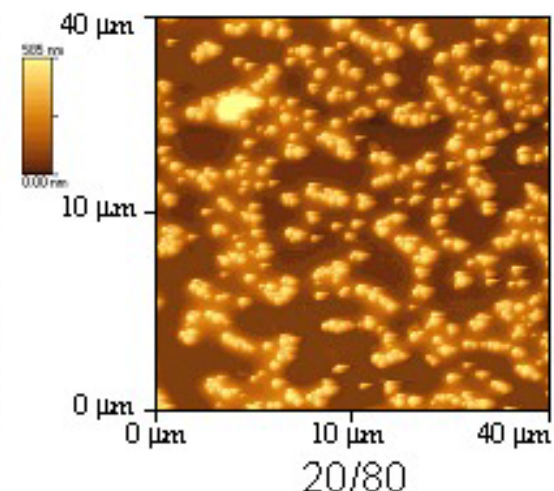

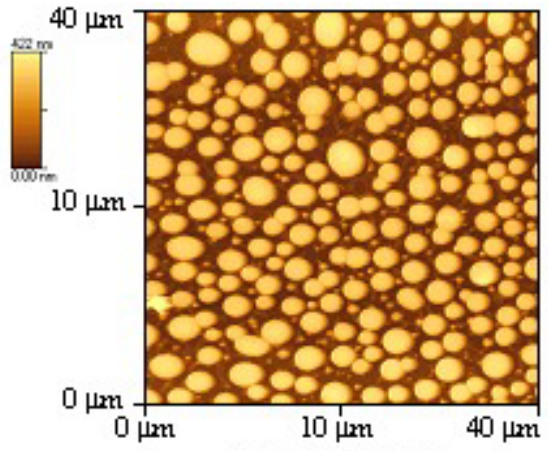

$64 / 10 / 10 / 16$

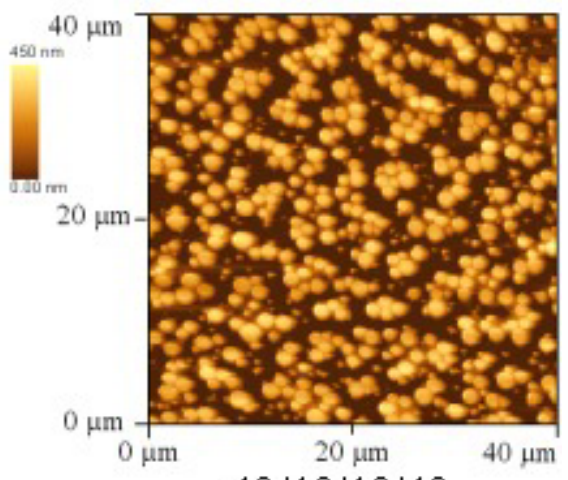

$40 / 10 / 10 / 40$

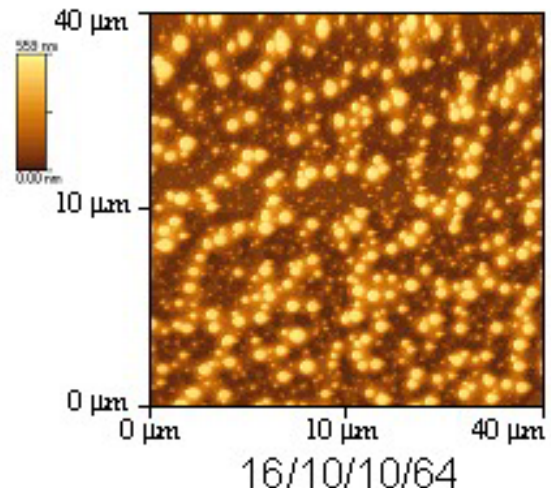

Fig. 5. OM and AFM images of polymer blends. Top: left: OM image PMMA/PnBA (80/20); middle: AFM image PMMA/PnBA (80/20); right: AFM image PMMA/PMMA$b$-PS/PS- $b-P n B A / P n B A=64 / 10 / 10 / 16$. Middle: left: OM image PMMA/PnBA (50/50); middle: AFM image PMMA/PnBA (50/50); right: AFM image PMMA/PMMA-b-PS/PS$b$-PnBA/PnBA = 40/10/10/40. Bottom: left: OM image PMMA/PnBA (20/80); middle: AFM image PMMA/PnBA (20/80); right: AFM image PMMA/PMMA- $b-P S / P S-b-P n B A /$ $\operatorname{PnBA}=16 / 10 / 10 / 64$ 
After the two diblock copolymers had proven their dispersing efficiency in the binary systems they both were employed in the actually interesting system PMMA/PnBA. OM and AFM images of blends with different compositions are shown in Fig. 5.

On the left and in the middle, the system is shown without addition of a coupling agent; on the right, the system is shown after addition of $10 \%$ each of PMMA- $b-P S$ and PS- $b-P n B A$, respectively, as coupling agents. In row 1 of Fig. 5, PMMA forms the continuous elevated matrix and PnBA the dispersed lower one, in rows 2 and 3 PnBA forms the lower matrix which incorporates the elevated, dispersed PMMA phase. Obviously the addition of both diblock copolymers increases the distribution of PMMA in each case. This is also shown in Fig. 6, where the particle size distributions for PMMA/PnBA (50/50) and PMMA/PMMA- $b$-PS/PS- $b-P n B A / P n B A=40 / 10 / 10 / 40$ are plotted.

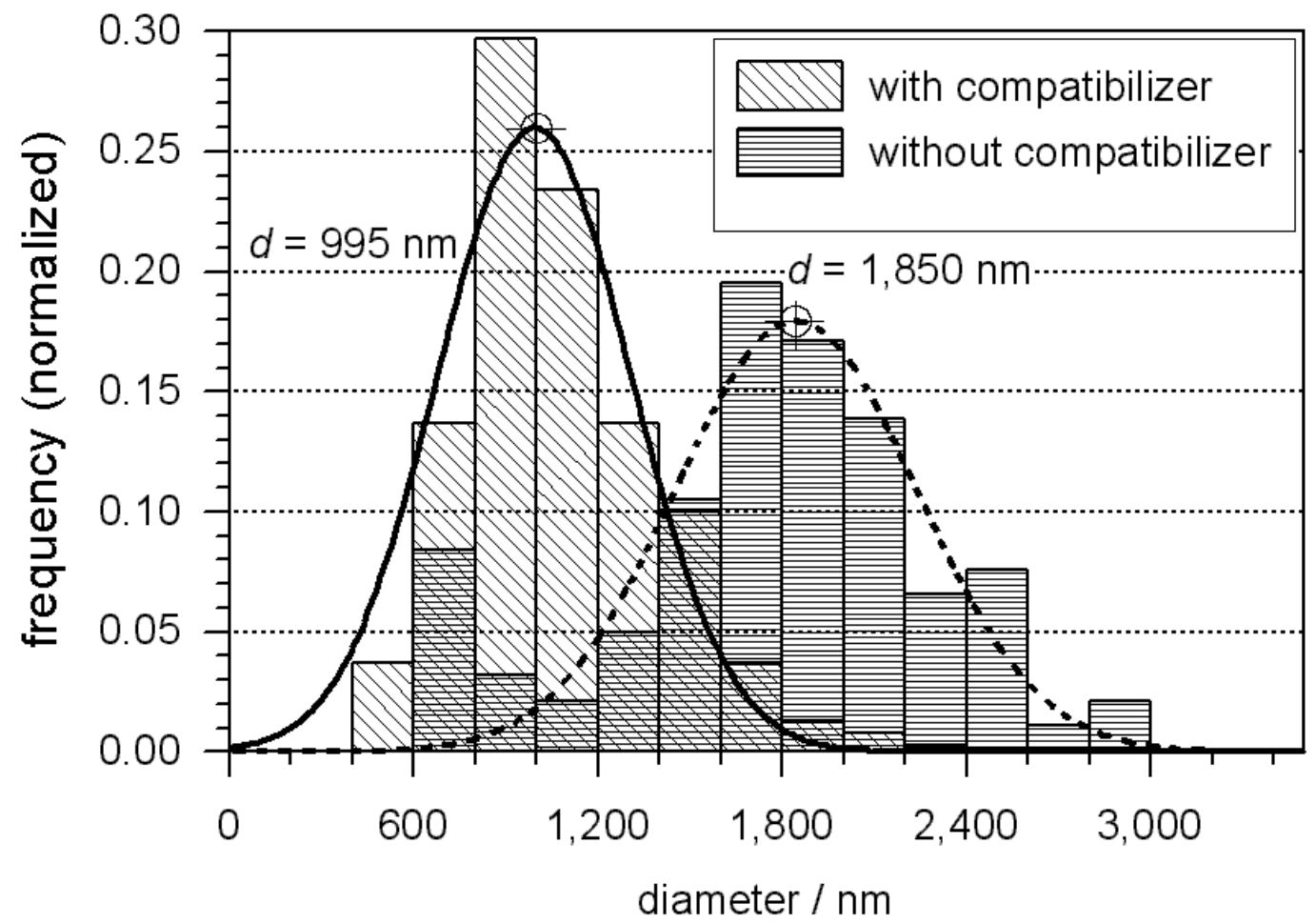

Fig. 6. Particle size distributions of the two blends $P M M A / P n B A=50 / 50$ and $P M M A /$ PMMA-b-PS/PS- $b-P n B A / P n B A=40 / 10 / 10 / 40$ in row 2 in Fig. 5

The diameter interval has been fixed in this case at $200 \mathrm{~nm}$. In the blend without addition of the coupling agent PMMA/PnBA 50/50, the smallest PMMA particles have a diameter of about $600 \mathrm{~nm}$, the largest of about $3000 \mathrm{~nm}$. The average particle diameter is $1850 \mathrm{~nm}$. In the blend with addition of coupling agent, the smallest PMMA particles have a diameter of about $400 \mathrm{~nm}$, the largest of about $2400 \mathrm{~nm}$, the portion of particles with a diameter larger than 2000 being very small. The particle size distribution is clearly narrower than in the blend without addition of coupling agent. Its average particle diameter is $995 \mathrm{~nm}$.

All systems investigated show that the addition of an individual coupling agent or a coupling agent system effects a reduction of the particle diameter on the one hand, and on the other that distributions become more uniform and narrower. This means that both the individual diblock copolymers and also the new coupling agent system 
are effective on a microscopic level: the systems are stabilized with respect to separation and phase growth.

Moreover, with the aid of the TEM images the individual phases can be illustrated directly and we can in particular make statements on the arrangement of the diblock copolymers. Fig. 7 shows a corresponding schematic illustration of the total blend system PMMA/PMMA- $b-\mathrm{PS} / \mathrm{PS}-b-\mathrm{PnBA} / \mathrm{PnBA}$. By contrasting with $\mathrm{RuO}_{4}$, exclusively styrene units of the diblock copolymers are thus selectively coloured. TEM images were taken from cuts from test samples of such blends, prepared by melt mixing. Fig. 7 shows a section $1.1 \mu \mathrm{m} \times 1.1 \mu \mathrm{m}$ of a system with both coupling agents, too.
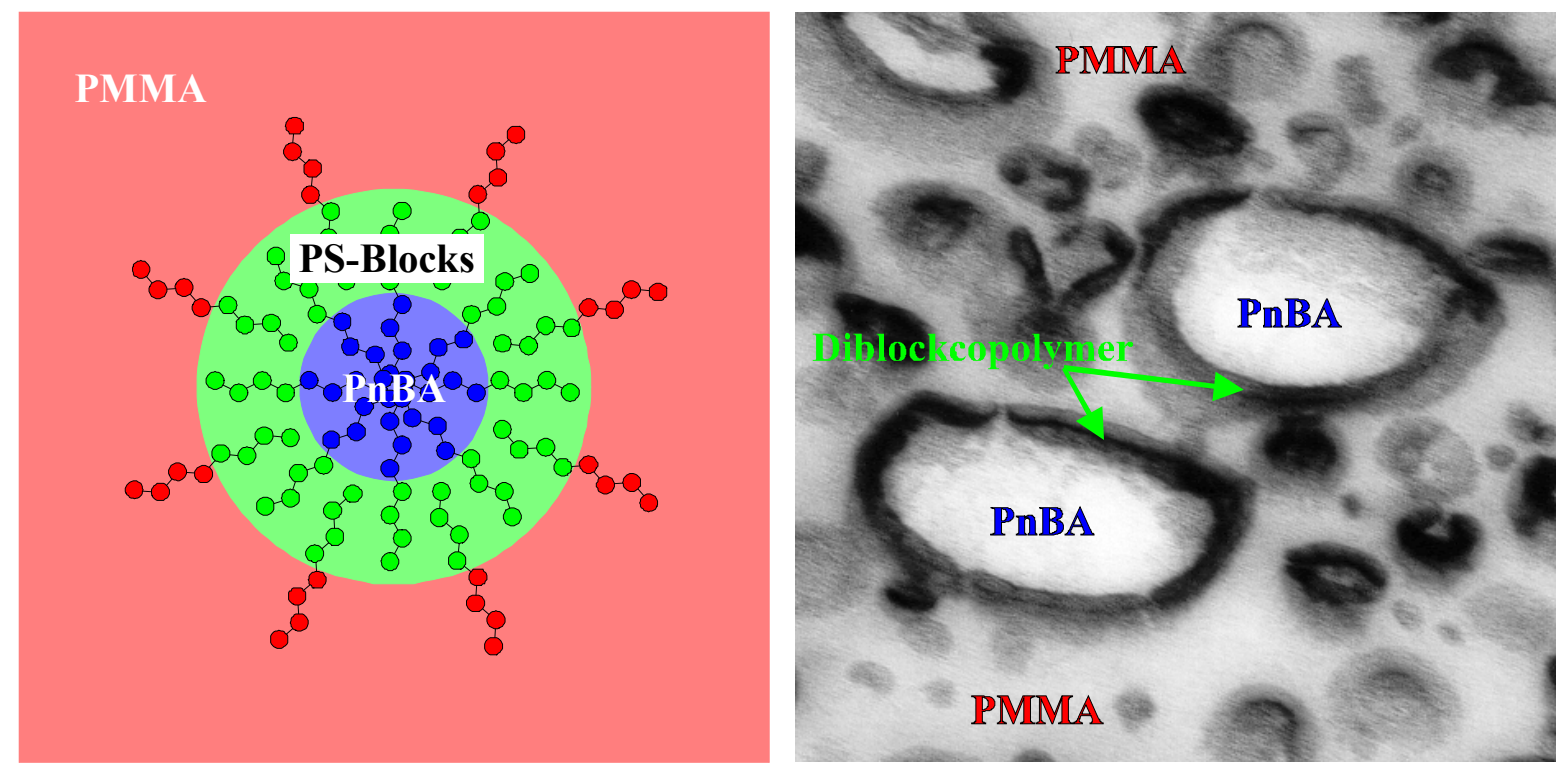

Fig. 7. Left side: schematic illustration of the polymer blend system PMMA/PMMA- $b-$ PS/PS- $b$-PnBA/PnBA; right side: TEM image of a blend with two coupling agents with a ratio of PMMA/PMMA- $b$-PS/PS- $b-P n B A / P n B A=64 / 10 / 10 / 16$

The TEM image shows that the diblock copolymers are arranged at the phase interface between PMMA and PnBA; this can be clearly recognized by the black ring layer around the disperse phase. The diblock copolymers do not form their own separate phase; completely black particles cannot be detected. The arrangement thus corresponds to the basic ideas of this elaboration and is an essential prerequisite for the effectiveness of the coupling agent system.

\section{Mechanical properties of PMMA/PMMA-b-PS/PS-b-PnBA/PnBA blends}

Optimization of the character profile of heterogeneous synthetic materials is particularly focussed on the impact strength. For this purpose, brittle, amorphous thermoplastics are modified by soft elastomers to become impact resistant. This also applies to the system investigated in this study: PMMA is a brittle and hard synthetic material, PnBA a soft one, which can however not be classified as an elastomer since it has no wide-mesh cross-linkage. PMMA is always used in excess and acts as matrix material. After we had found in the first part of our investigations that our copolymers really arrange at the interface in blends of our two immiscible homopolymers we checked in the second part the influence of this arrangement on some mechanical properties of the new blends. 


\section{Charpy tests for impact strength}

Impact strength was tested by way of the impact-bending test according to Charpy. Its value represents a measure of the toughness of the material. Test samples have been produced from four blends and the impact strength measured; the phase weight ratio PMMA to PnBA was always about $2: 1$, one blend (PMMA/PnBA 65/35) without addition of the coupling agent system, two blends ( PMMA/PMMA- $b-P S / P S-b-P n B A /$ $\mathrm{PnBA}=58.5 / 5 / 5 / 31.5$ and $=52 / 10 / 10 / 28)$ with a different portion of the coupling agent system. Due to the composition of the diblock copolymers, the total contents of PMMA/PS/PnBA were about $61 / 5 / 34$ and $57 / 10 / 33$, respectively. Thus the concentration of hard (PMMA and PS) and soft (PnBA) material in both blends was comparable. Furthermore a ternary blend of the homopolymers with PMMA/PS/PnBA $=57 / 10 / 33$ was tested. The absolute portion of the components in the ternary blend corresponds to the portion of the components of the binary blends with $10 \%$ diblock copolymer each. The difference is that $10 \%$ styrene are contained in the ternary blend in the form of homopolymer PS, whereas in the coupled blend it is a composite of the diblock copolymers. Tab. 2 shows that the impact strength and thus the toughness of the blends increase with the portion of coupling agent growing from 3.6 $\mathrm{kJ} / \mathrm{m}^{2}$ to $6.7 \mathrm{~kJ} / \mathrm{m}^{2}$.

Tab. 2. Charpy impact strength of some selected PMMA/PnBA blends

\begin{tabular}{|c|c|c|}
\hline System & Weight ratio & $\begin{array}{l}\text { Impact strength } \\
\text { in } \mathrm{kJ} / \mathrm{m}^{2}\end{array}$ \\
\hline PMMA/PnBA & $65 / 35$ & 3.6 \\
\hline PMMA/PMMA-b-PS 2/PS-b-PnBA 2/PnBA & $58.8 / 5 / 5 / 31.5$ & 6.1 \\
\hline PMMA/PMMA-b-PS 2/PS- $b$-PnBA 2/PnBA & $52 / 10 / 10 / 28$ & 6.7 \\
\hline PMMA/PS/PnBA & $69 / 10 / 21$ & 3.2 \\
\hline
\end{tabular}

Even small additions of diblock copolymers have the effect of almost doubling the strength; with more than $5 \%$, the increase is only slight, and the curve approaches a limit value. These values make clear that also considerably smaller additions of coupling agent than $10 \%$ are sufficient.

The impact strength of the ternary blend differs significantly from that of the blend with $10 \%$ diblock copolymer each; it is merely $3.2 \mathrm{~kJ} / \mathrm{m}^{2}$ and thus lies below the value of the binary blend of PMMA/PnBA 65/35. It is thus decisive whether styrene is present as homopolymer or as composite part of the diblock copolymers. However, it could have been possible that a homopolymer, polystyrene in this case, acts as phase coupler. In this case, the application of more expensive coupling agents would be hardly useful. However, distinct differences are prevailing here and the improvement of the mechanical characteristics is an effect of the addition of the coupling agent system.

The absolute values and the increase of impact strength in our blends can be compared with those of Cho et al. [12] who investigated the effect of rubber particle size on the impact strength of core-shell type particles made up from a PnBA core and a PMMA outer shell. For all rubber particle sizes impact strength increased with increasing rubber phase content (weight fraction), passing a maximum value at higher rubber concentration, which is said to be related to the decrease of modulus 
and yield stress. We cannot exclude that in our case the addition of higher amounts of diblock copolymers causes a decrease in impact strength, too.

\section{Strain-stress measurements}

Due to practical reasons we could not synthesize PMMA/PS and PS/PnBA block copolymers in high amounts sufficient to prepare test specimens for large commercial injection moulding machines. The used micro injection moulding machine provided tensile bars not obeying common DIN norms for such tests. Therefore all results of strain-stress measurements can only be compared with each other on a relative scale. Along a strain/stress curve properties like Young's modulus, yield stress, tensile strength at break and elongation at break can be determined. Of interest was whether these properties can be increased by the addition of PMMA/PS and $\mathrm{PS} / \mathrm{PnBa}$ block copolymers to PMMA/PnBA binary blends as proposed by Balazs and coworkers. For that purpose tensile specimens were produced from ternary PMMA/PMMA- $b$-PS/PS- $b-P n B A / P n B A$ polymer blends of compositions $88 / 5 / 5 / 2$, $77 / 10 / 10 / 3,72 / 5 / 5 / 18$, and 64/10/10/16, respectively. Corresponding to the composition of the block copolymers the ratio PMMA/PS/PnBA in these polymer blends was 90.6/4.25/5.15, 82.2/8.5/9.3, 74.8/4.65/20.55, and 69.6/9.3/21.1, and the ratio of rigid (PMMA+PS) and soft (PnBA) material resulted to 94.85/5.15, 90.7/9.3, 79.45/20.55, and 78.9/21.1, respectively, comparable to the binary PMMA/PnBA blends with a ratio of rigid and soft polymer of $95 / 5,90 / 10$, and $80 / 20$. The corresponding values for all samples are listed in Tab. 3.

Tab. 3. Young's moduli, yield stress, tensile strength at break, and elongation at break for different PMMA/PnBA polymer blends at room temperature

\begin{tabular}{cccccc}
\hline Blend & $\begin{array}{c}\text { Composition } \\
\text { PMMA/PS/PnB } \\
\text { in wt.-\% }\end{array}$ & $\begin{array}{c}\text { Young's } \\
\text { modulus } \\
\text { in GPa }\end{array}$ & $\begin{array}{c}\text { Yield stress } \\
\text { in GPa }\end{array}$ & $\begin{array}{c}\text { Tensile strength } \\
\text { at break } \\
\text { in GPa }\end{array}$ & $\begin{array}{c}\text { Elongation } \\
\text { at break } \\
\text { in \% }\end{array}$ \\
\hline 1 & $95 / 0 / 5$ & 3.222 & 0.063 & 0.052 & 8.0 \\
2 & $90.6 / 4.25 / 5.15$ & 3.087 & 0.063 & 0.047 & 25.3 \\
3 & $90 / 0 / 10$ & 2.661 & 0.040 & 0.040 & 2.3 \\
4 & $82.2 / 8.5 / 9.3$ & 2.778 & 0.057 & 0.051 & 4.7 \\
5 & $80 / 0 / 20$ & 1.455 & 0.022 & 0.017 & 1.9 \\
6 & $74.8 / 4.65 / 20.55$ & 1.421 & 0.014 & 0.013 & 1.4 \\
7 & $69.6 / 9.3 / 21.1$ & 0.871 & 0.009 & 0.008 & 1.7
\end{tabular}

The properties for the binary 95/5, 90/10 and 80/20 PMMA/PnBA polymer blends (rows 1,3 and 5 in Tab. 3) decreased as expected with increasing content of the rubber component. The standard deviation of the values was less than $5 \%$. In the ternary blends the diblock copolymers should act like a molecular Velcro to bind together the two homopolymer matrices, as was claimed by Balasz et al. [4]. They had investigated the stress-strain behaviour of a 1:1 w/w mixture of PMMA/poly(ethyl acrylate) (PEA) polymer blends and of a 0.3:0.3:0.2:0.2 mixture of PMMA and PEA with PMMA/PS and PS/PEA graft copolymers as compatibilizers. The authors determined Young's modulus, stress at break and tensile strength of both blends. 
Young's moduli of both mixtures were 0.0265 and $0.0635 \mathrm{GPa}$, respectively. Due to the very high content of the rubber phase these values are extremely low in comparison to Young's moduli of pure PMMA and pure PS, which are usually about 3.2 and 3.4 GPa, respectively. The authors trace the increase in Young's modulus to the addition of the graft copolymers. Unfortunately their composition was not reported, so that the reliability of the results cannot be estimated. It cannot be excluded that these small changes are perhaps more due to an increase of the content of the overall rigid phase than to the effect of the diblock copolymers.

Our blends contained much more rigid polymer, therefore, they cannot directly be compared with those of Balazs et al. At first it is obvious that the values of all variables decrease with increasing content of PnBA. Furthermore, for comparison, three groups of our results could be formed, like those of blends $1+2$, blends $3+4$, and blends 5, 6 and 7. The changes in each group are different. In group 1 with about $95 \%$ overall rigid material Young's modulus, yield stress and tensile strength at break showed a low decrease after the addition of the two block copolymers, yield stress remained nearly unchanged and the elongation at break increased by more than a factor of three. In group 2 with about $90 \%$ overall rigid material the values of all variables of the ternary blends are a bit higher than those of the binary blends, the elongation at break being doubled. In group 3 with about $80 \%$ overall rigid material the values of all variables for ternary blends are lower than for the binary samples, especially when about $10 \%$ of the matrix PMMA is substituted by PS stemming from the block copolymers. All in all the highest influence of the added two diblock copolymers seems to be exerted in the three groups on the elongation at break.

\section{Conclusions}

PMMA/PS and PS/PnBA diblock copolymers act well as compatibilizers in binary PMMA/PS and PS/PnBA polymer blends. Their addition appreciably reduces the width of the particle size distribution and the medium particle diameter of the dispersed phase as could be proven by scanning force microscopy of thin polymer blend films. In ternary systems PMMA/PMMA- $b$-PS/PS- $b$-PnBA/PnBA the two diblock copolymers form no own phase but arrange at the interface between PMMA and PnBA as TEM pictures clearly show. They enhance the toughness of such blends with increasing diblock copolymer concentration up to less than $10 \mathrm{wt} . \mathrm{\%}$. Their effect on mechanical properties like Young's modulus, yield stress and tensile strength at break is not very marked under our conditions, their major influence seems to be on the elongation at break. The reason for these observations may be that adding two diblock copolymers in the mentioned way to two different homopolymers may have two consequences: on the one hand they could increase some mechanical properties due to the Velcro effect at the interface between the homopolymers. On the other hand the content of the rubber phase will be increased, yielding a negative effect on those properties. The question is which effect is the overwhelming one.

[1] Balazs, A. C.; Gersappe, D.; Gross, N. A.; Lyatskaya, Y.; J. Phys. Chem. 1966, 100, 1449.

[2] Brown, H. R.; Char, K.; Deline, V. R.; Macromolecules 1993, 26, 4155.

[3] Teyssie, P.; Fayt, R.; Jerome, E.; J. Polym. Sci., Polym. Phys. 1989, 27, 775. 
[4] Balazs, A. C.; Gersappe, D.; Irvine, D.; Liu, Y.; Pfeiffer, D. G.; Rafailovich, M.; Schwarz, S.; Sokolov, J.; Science 1994, 265, 1072.

[5] Balazs, A. C.; Forster, D. P.; Israels, R.; Macromolecules 1995, 28, 218.

[6] Chu, J. H.; Paul, D. R.; Polymer 1999, 40, 2687.

[7] Xie, H. Q.; Zhou, S. B.; J. Macromol. Sci., Chem. 1990, A27, 491.

[8] Nelliappan, V.; El-Aasser, M. S.; Klein, A.; Daniels, E. S.; Roberts, J. E.; J. Polym. Sci., Polym. Chem. 1996, 34, 3173.

[9] Nelliappan, V.; El-Aasser, M. S.; Klein, A.; Daniels, E. S.; Roberts, J. E.; J. Polym. Sci., Polym. Chem. 1996, 34, 3183.

[10] Nelliappan, V.; El-Aasser, M. S.; Klein, A.; Daniels, E. S.; Roberts, J. E.; Pearson, R. A.; J. Appl. Polym. Sci. 1997, 64, 581.

[11] Cho, K.; Yang, J.; Park, C. E.; Polymer 1997, 38, 5161.

[12] Cho, K.; Yang, J.; Park, C. E.; Polymer 1998, 39, 3073.

[13] Wootthikanokkhan, J.; Burford, R. P.; Chaplin, R. P.; J. Appl. Polym. Sci. 1996, $62,835$.

[14] Schmalbrock, U.; Bandermann, F.; Makromol. Chem. 1993, 194, 2543.

[15] Rosa-Zeiser, A.; Weilandt, E.; Hild, S.; Marti, O.; Meas. Sci. Technol. 1997, 8, 1333.

[16] Sawyer, L. C.; Grubb, D. T.; "Polymer Microscopy", Chapman and Hall, London 1987, p. 27.

[17] Smith, G. D.; Russel, T. P.; Kulasekere, R.; Ankner, J. F.; Kaiser, H.; Macromolecules 1996, 29, 4120.

[18] Pellegrini, N. N.; Sikka, M:; Satija, S. K.; Winey, K. I.; Macromolecules 1997, 30, 6640.

[19] Lee, C.; Chen, Y.; Chiu, W.; J. Appl. Polym. Sci. 1998, 69, 13.

[20] Russell, T. P.; Menelle, A.; Hamilton, W. A.; Smith, G. S.; Satija, S. K.; Majkrzak, C. F.; Macromolecules 1991, 24, 5721.

[21] Macosko, C. W.; Guégan, P.; Khandpur, A. K.; Nakayama, A.; Marechal, P.; Inoue, T.; Macromolecules 1996, 29, 5590.

[22] Vollmert, B.; Angew. Makromol. Chem. 1968, 3, 1.

[23] Lee, M. S.; Lodge, T. P.; Macosko, C. W.; J. Polym. Sci., Part B: Polym. Phys. 1997, 35, 2835. 